\title{
PERFORMANCE OF AUTOMOTIVE SLI BATTERY UNDER CONSTANT CURRENT CONSTANT VOLTAGE CHARGE ALGORITHM IN SOLAR PV APPLICATION
}

\author{
D. Anipa and P.Y. Okyere \\ Faculty of Electrical and Computer Engineering, \\ College of Engineering, \\ Kwame Nkrumah University of Science and Technology, Kumasi, Ghana
}

\begin{abstract}
The high initial cost of deep-cycle PV battery and its high replacement cost constitute an important barrier to the deployment of solar PV technology, particularly in poor rural settings. Battery lifetime depends on effective charge control and load management. In this project, a cost-effective $12 \mathrm{~V}$ battery charge controller was developed to implement constant current constant voltage charge algorithm in small-sized stand-alone solar PV systems. The algorithm was tested on automotive SLI battery instead of deep-cycle PV battery to further reduce overall system cost. The battery state of charge (indicated by specific gravity), which is an indicator of algorithm performance, was monitored over 200 daily charge/discharge cycles. The value of the specific gravity ranged from 1.250 to 1.260, demonstrating the effectiveness of the control algorithm.
\end{abstract}

Keywords: Battery charge control, Solar PV lighting, Renewable energy technology, Rural electrification

\section{INTRODUCTION}

Deep-cycle lead-acid batteries have become the most widely used energy storage system in solar photovoltaic (PV) applications. These batteries are, however, expensive and are partly responsible for the high up-front cost associated with solar PV systems.

Currently, PV system designers are turning to the use of shallow-cycle automotive SLI (starting, lighting, and ignition) batteries, particularly in poor rural settings because they are relatively cheap and are widely available on local markets (Instituto de Energia Solar, 1998).

Automotive SLI batteries, by their design, are not appropriate for solar PV applications. They have thin plates and can discharge high currents for short periods only. In addition, their charging requirements in PV applications are not well known and manufacturers seldom provide adequate data on them. Their use in PV systems will require, therefore, optimal recharge and careful load management in order to improve their cycle 
life and make them competitive with their deepcycle counterparts.

Battery life and reliability of a stand-alone PV system depend largely on effective battery charge control. For example, poor charge control can accelerate battery ageing thereby necessitating premature replacement (Hollenkamp et al., 1992; Hans-Georg and Dirk, 1996). The charge algorithm for most PV lead-acid batteries is determined by the battery manufacturer. Depending on the level of sophistication of the charger technology, the algorithm may implement several charging modes or stages including bulk, absorption, equalization and float modes within a charging cycle. The bulk charge mode supplies constant current to the battery as its voltage builds up. The absorption stage is an over-charge stage where the charger maintains an elevated constant voltage while the battery draws current until full charge is attained. The equalization stage is a controlled combination of bulk and absorption modes with different voltage limits. It equalizes the specific gravity of electrolyte and the voltage of the cells. The float charge mode provides a constant voltage to the battery at minimal charge current. This mode can maintain a fully charged battery indefinitely against selfdischarge (Laszlo, 1999). For a selected battery, the stages implemented in the charge algorithm and the order in which the control program sequences these stages in the cycle impact significantly on the charge efficiency. The charge efficiency or the charge acceptance is the ratio between the energy removed from the battery during discharge and the energy used during the recharge to restore the original capacity (Don et al., 2003).

Charge controllers are classified mainly according to the method by which the charge current is varied. The less expensive charge controllers use simple devices such as a comparator and relay to vary the charge current in an on-off manner. The on-off control strategy does not implement the absorption stage which is necessary for the battery to attain full charge. The expensive control- lers, on the other hand, often use programmable devices such as microcontrollers to either vary the charge current linearly or to deliver it in pulses whose width can be varied (Pulse-WidthModulation). The programmable device offers the flexibility to implement a wide range of charge control algorithms including fuzzy logic control (Rahim et al., 2006).

Charging a PV battery is a complex process because the energy to charge the battery is limited and is highly variable due to changes in weather (Kenneth and Daniel, 1997). Current laboratory and field tests have consistently identified incomplete recharge of PV batteries as a result of random charging and inappropriate control strategy such as on-off control. Incomplete recharge has been found to be the predominant cause of premature capacity loss, leading to reduced rated cyclelife (Rainer and Dirk, 2001; Tom, 2002). Achieving optimal battery charge will thus require identification of the charging requirements which include appropriate regulation voltages with temperature compensation and adequate PV array sizing. It will also require appropriate stages for the charge control algorithm and the sequence in which these stages are applied during the charge cycle. In this project, a Unitrode UC2906 integrated circuit was used to develop a cost-effective battery charge controller to implement a 3-stage charge control algorithm (Bulk-AbsorptionFloat). By adding a few external resistors and a transistor, the UC2906 implements the charge control algorithm based on the appropriate regulation voltages with ambient temperature compensation (Unitrode Corporation, 1999). This provides a significant reduction in design and construction effort as well as the overall cost of the charge controller. It also enhances controller reliability and maintainability because of the low component count. The algorithm was tested on an arbitrarily selected off-the-shelf automotive SLI battery in a solar PV lighting application. The specific gravity, which represents the state of charge of the battery, and the battery terminal voltage were monitored in order to determine the

86 Journal of Science and Technology, Vol. 28, No. 2, August, 2008 
suitability of the charger-battery combination in solar PV lighting application.

\section{MATERIALS AND METHODS}

Figure 1 shows the functional block diagram of an actual solar PV lighting system to monitor the specific gravity and terminal voltage of the SLI battery under constant current constant voltage charge algorithm. The battery charge controller (shown in broken-line box) comprises a battery voltage sensing and charge control unit. It was realized by connecting a network of resistors to the UC2906 IC, whose output drives an external pass-transistor to linearly regulate the charge current to the battery. Low-voltage load disconnect (LVD) and dawn-dusk switches were also incorporated for battery load management. The two switches protect the battery against overdischarge. An 18-watt 2-foot fluorescent light fitted with electronic ballast was used as the load and was powered by a 75Ah flooded automotive lead-acid battery. In order to measure and $\log$ the battery terminal voltage and charge current, a 21X Campbell Micro-logger (not shown) was set up. A hand-held hydrometer was used to measure the specific gravity of the electrolyte. The source of solar energy was a $45.3 \mathrm{Wp} 18.0 \mathrm{~V}$ PV module with peak and short-circuit current rating of 3.02A and 3.25A respectively. The experiment was carried out under room temperature condition.

\section{Sizing and design of system components PV module and battery}

The availability of adequate solar energy to charge the battery requires the ampere-hour (Ah) of the PV module to be greater than the Ah of the load. The ratio, $\mathbf{A} \mathbf{h}_{\mathbf{P V}}: \mathbf{A} \mathbf{h}_{\mathbf{L o a d}}$, which typically ranges from 1.1 to 1.5 , implicitly determines how much time the battery spends in the discharged state (Don et al., 2003). A high ratio minimizes sulfation but leads to increased cost of the PV generator. The fluorescent lamp (load) draws 1A from the $12 \mathrm{~V}$ battery and is required to operate for 11 hours (6:30 p.m. - 5:30 a.m.) daily, which is equivalent to $11 \mathrm{Ah}$. The lowest monthly Peak Sun Hours (PSH) for Ghana is 4.38 (Ministry of Energy, 2005). For a module peak current of $3.02 \mathrm{~A}$, the $\mathrm{PV}$ generator $\mathrm{Ah}$ is 13.23 , and the ratio is calculated as 1.2. The battery capacity, $\mathrm{C}$, is calculated for a single day autonomy as

$$
C=\frac{11 A h \times 1_{\text {day -autonomy }}}{15 \%_{\text {depthofdis } \operatorname{ch} \arg e}}=73.3 A h(\cong 75 A h)
$$

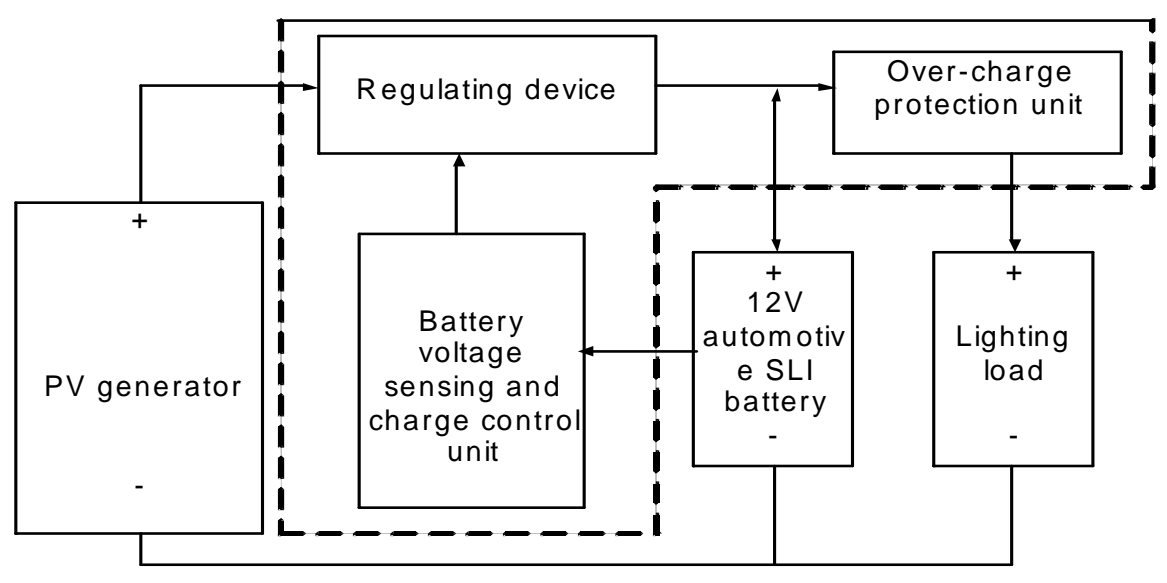

Fig. 1: Functional block diagram of experimental setup 


\section{Voltage sensing and charge control unit}

This unit was designed using a UC 2906 IC, a network of resistors and decoupling capacitors. The values of the resistors were calculated based on the selected regulation voltages, which depend on battery design. Design based on leadantimony requires high voltage to attain full charge but suffers from excessive gassing and water depletion. The lead-calcium design was introduced to avert the problem of excessive gassing but the nature of the design prevents the battery from being fully charged. The leadantimony/lead-calcium hybrid combines the advantages of both designs but loses the deep cycling characteristic of the lead-antimony only design (Siemens Solar Industries, 1998). Gassing helps cell equalization, which is also a remedy for stratification. It, however, accelerates grid corrosion and increases internal resistance hence battery ageing (Calabek et al., 1996; Alber, 1998). In view of the conflicting requirements and the absence of manufacturers' data, the selection of appropriate regulation voltages was guided by the voltage setting generally used in automobile charge regulators $(13.2 \mathrm{~V}$ to $15.3 \mathrm{~V}$ ) and the random nature of PV battery charging. Two sets of regulation voltages were investigated to verify the effect of varying the set-points of the charge controller on the selected battery (Table 1).

Using the final setting, the resistor values were calculated as follows (Figure 2).

$$
\begin{aligned}
& V_{O C}=V_{R E F}\left[1+\frac{R_{A}}{R_{B}}+\frac{R_{A}}{R_{C}}\right] \\
& =V_{F}+V_{R E F} \frac{R_{A}}{R_{C}}
\end{aligned}
$$

where $\mathrm{V}_{\mathrm{REF}}=2.3 \mathrm{~V}$ (internal reference voltage of the UC2906 IC). Set $R_{A}$ to $100.0 \mathrm{k} \Omega$ so that $R_{B}=$ $20.0 \mathrm{k} \Omega$ and $\mathrm{R}_{\mathrm{C}}=287.5 \mathrm{k} \Omega$ (nearest standard value is $300 \mathrm{k} \Omega$ ).

$$
R_{S}=\frac{0.25 \mathrm{~V}}{3.02 \mathrm{~A}}=0.080 \Omega
$$

where $3.02 \mathrm{~A}$ is the peak current of the PV generator.

A $0.015 \Omega$ current sense resistor $\left(R_{S}\right)$ was obtainable in place of the calculated $0.080 \Omega$. This implies a maximum allowable charge current of 16.7A; the PV generator supplies a maximum current of only 3.02A. The UC2906 IC uses an in -built temperature tracking unit to compensate $\mathrm{Voc}$ and $\mathrm{V}_{\mathrm{F}}$ at $-3.9 \mathrm{mV} /{ }^{\circ} \mathrm{C}$. High ambient temperatures will therefore not result in overheating of battery provided it is in proximity of the controller. A high-gain $\left(\mathrm{h}_{\mathrm{fe}}=1000\right) 5 \mathrm{~A}$ PNP passtransistor (TIP 125) was used to linearly regulate the PV generator current to charge the battery. A schottky diode between the pass-transistor and the battery prevented reverse current flow to the generator during low insolation.

Table 1: Regulation voltages

\begin{tabular}{lccc}
\hline & $\begin{array}{c}\text { Voc } \\
\text { (Regulation set-point } \\
\text { for over-charge) }\end{array}$ & $\begin{array}{c}\mathbf{V}_{\mathbf{F}} \\
\text { (Float voltage) }\end{array}$ & LVD \\
\hline Initial setting & $13.8 \mathrm{~V}$ & $12.8 \mathrm{~V}$ & $11.3 \mathrm{~V}$ \\
Final setting & $14.6 \mathrm{~V}$ & $13.8 \mathrm{~V}$ & $11.4 \mathrm{~V}$ \\
\hline
\end{tabular}

88 Journal of Science and Technology, Vol. 28, No. 2, August, 2008 


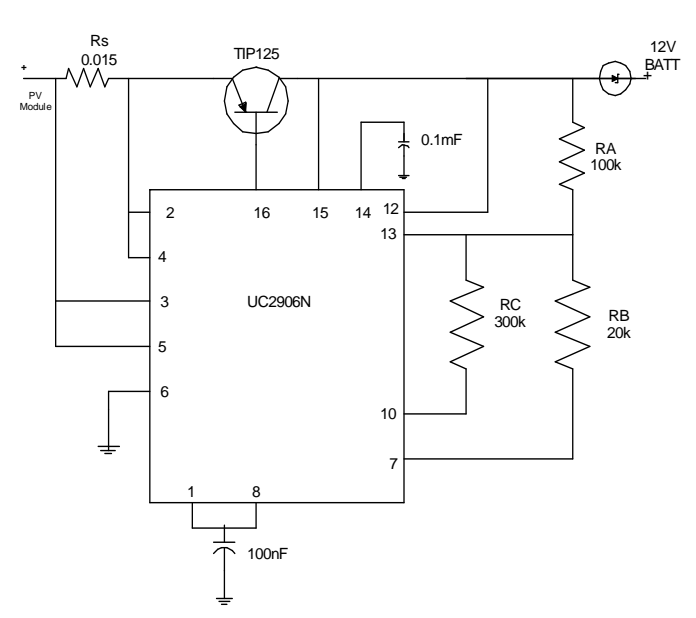

Fig. 2: Circuit diagram of battery voltage sensing and charge control unit.

\section{Load management unit}

The LVD and the dawn-dusk switches protect the battery against over-discharge and user negligence respectively.

\section{Low voltage load disconnect (LVD) switch}

When put on load, a fully charged $12 \mathrm{~V}$ lead-acid battery will discharge in a few minutes from float-charge voltage to about $12.5 \mathrm{~V}$. It then takes several hours, depending on the discharge rate, to reach the low voltage load disconnect setpoint (Butler, 1997). A typical LVD set-point for $12 \mathrm{~V}$ deep-cycle PV batteries is $10.8 \mathrm{~V}$. The circuit of Figure 3 monitors the SLI battery voltage and disconnects the load at $11.4 \mathrm{~V}$ (final setting

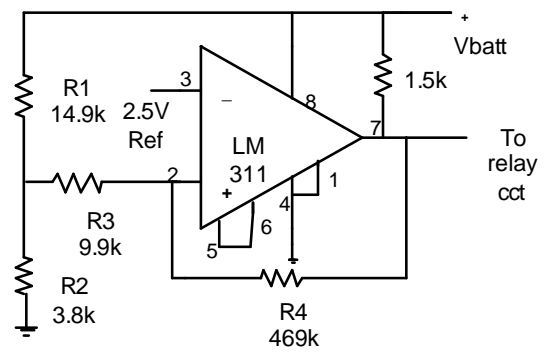

Fig. 3: Circuit diagram of LVD switch of Table 1). An LM 317 voltage regulator sets a reference voltage of $2.5 \mathrm{~V}$ at input pin 3 of the $\mathrm{LM}$ 311 comparator. Resistors R1 and R2 form a potential divider circuit that scales down the instantaneous battery voltage. Resistors R3 and R4 set a hysteresis of $1.2 \mathrm{~V}$ so that when the load is disconnected at $11.4 \mathrm{~V}$, the battery will need to be recharged to at least $12.6 \mathrm{~V}$ before the load is reconnected.

\section{Dawn-Dusk switch}

The dawn-dusk switch protects the battery from over-discharge, which could result from user negligence. The switch disconnects the load during the day and reconnects it at night. The load is disconnected when the PV module voltage builds up at sunrise to the zener reference voltage of $2.7 \mathrm{~V}$ (Figure 4). It is reconnected when this voltage drops below $2.7 \mathrm{~V}$ at sunset. This reference voltage was arrived at by monitoring visibility at sunrise and sunset with different zener diodes in circuit. The maximum collector current of $6 \mathrm{~A}$ of the pnp transistor (TIP42) was selected to withstand the module short-circuit current. The LM 7805 voltage regulator maintains a constant voltage to a $6 \mathrm{~V}$ DC relay.

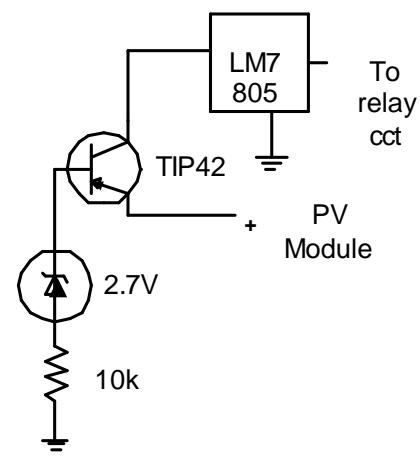

Fig. 4: Circuit diagram of dawn-dusk switch

\section{Monitoring procedure}

In order to determine conclusively the lifetime of a PV battery, actual cycle life data need to be obtained, which would require several years and a large number of batteries as samples. Since battery ageing process is continuous and fairly lin- 
ear, subjecting a selected battery to a reasonable number of cycles in a real PV application could help predict its lifetime under specified operating conditions.

With the initial regulation voltage settings the battery powered the 1A load for over 150 daily cycles (mid August 2005 - mid February 2006). The charge/discharge terminal voltage of the battery and weather station data (global solar radiation) were logged over the period. The specific gravity (SG) and temperature of the electrolyte were measured once a week using a hydrometer and thermometer. The settings were then reviewed to the final values indicated in Table 1 and the system operated for more than 120 additional daily cycles (mid February - mid July 2006). The electrolyte SG and temperature were measured once a day and the charging current (proportional to the voltage drop across the sense resistor $R_{S}$ ) as well as battery terminal voltage data logged. Weather station data was also logged.

\section{RESULTS}

Figures 5 to 8 represent some of the battery charge/discharge voltages and global radiation curves for the initial settings. Figures 9 to 14 also represent some of the battery charge/ discharge voltage, charge current, and global radiation curves for the final settings.

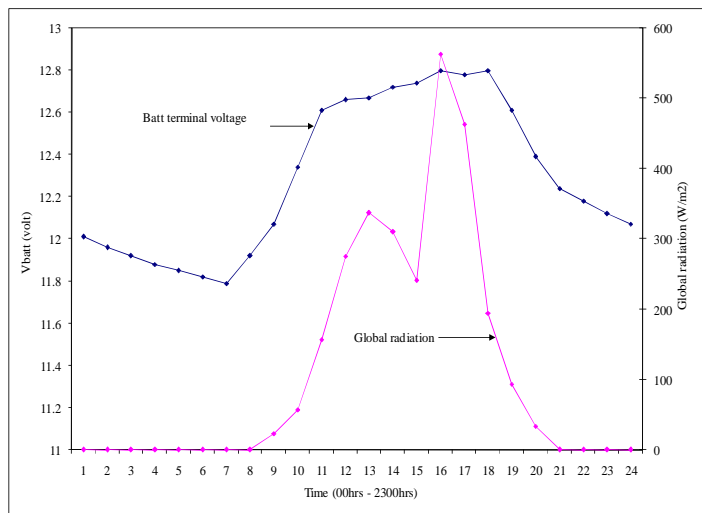

Fig. 5: Battery terminal voltage and Global radiation versus time $-\mathbf{2 2}^{\text {nd }}$ August 2005

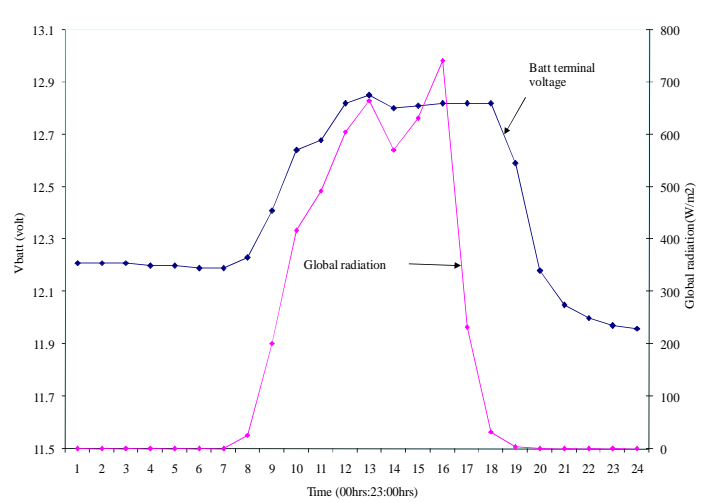

Fig. 6: Battery terminal voltage and Global radiation versus time $-5^{\text {th }}$ October 2005

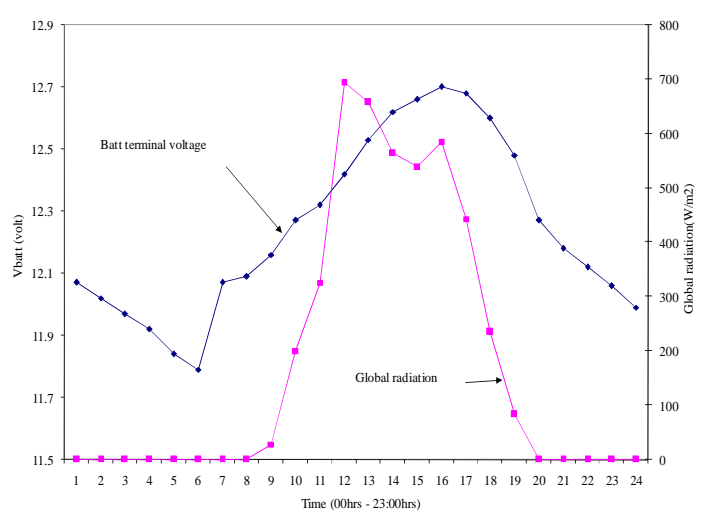

Fig. 7: Battery terminal voltage and Global radiation versus time $-17^{\text {th }}$ December 2005

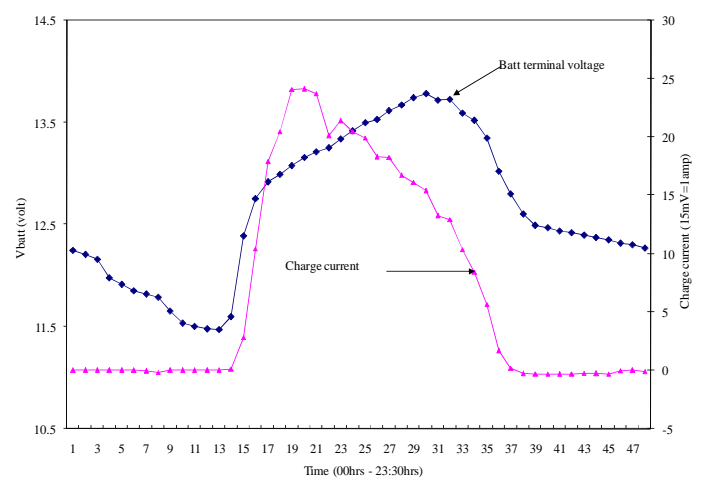

Fig. 8: Battery terminal voltage and Global radiation versus time $-5^{\text {th }}$ February 2006

90 Journal of Science and Technology, Vol. 28, No. 2, August, 2008 


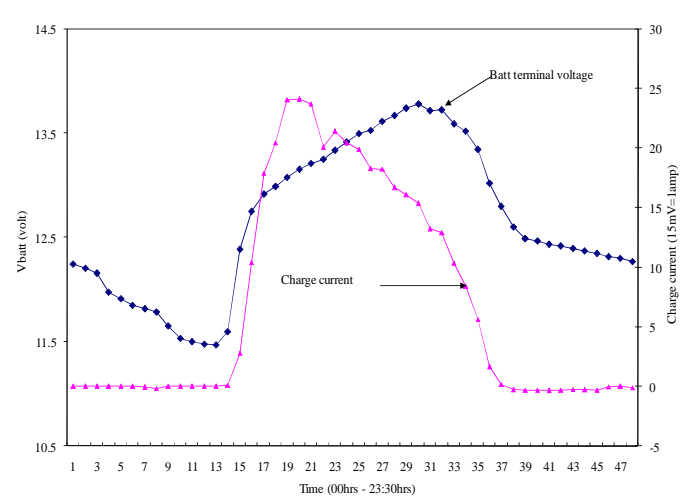

Fig. 9: Battery terminal voltage and charge current versus time $-19^{\text {th }}$ March 2006

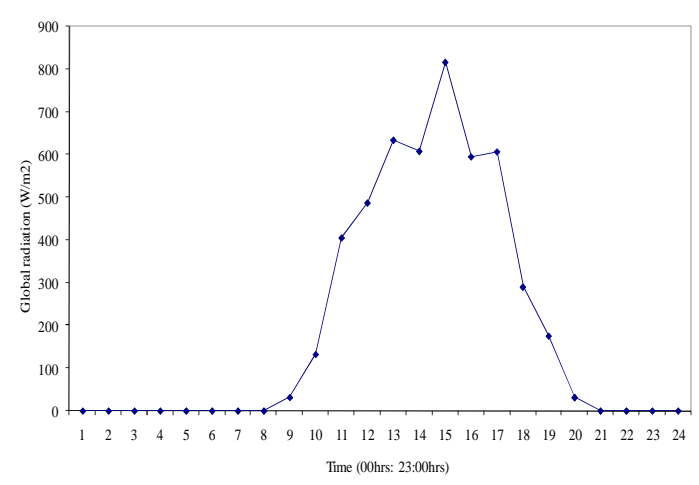

Fig. 10: Global radiation versus time $-19^{\text {th }}$ March 2006

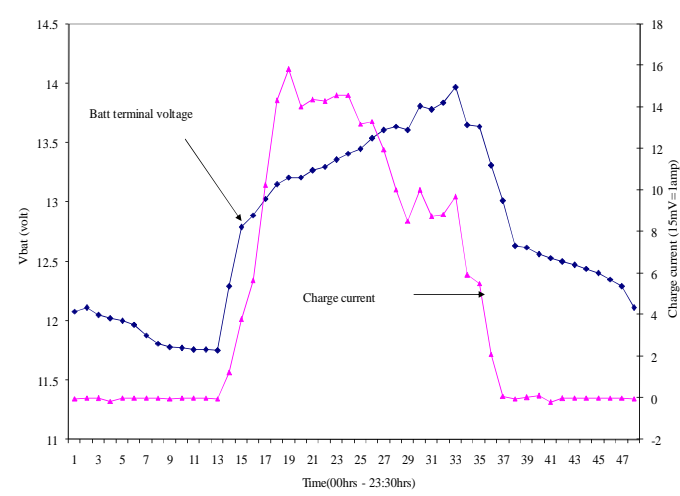

Fig. 11: Battery terminal voltage and charge current versus time $-19^{\text {th }}$ May 2006

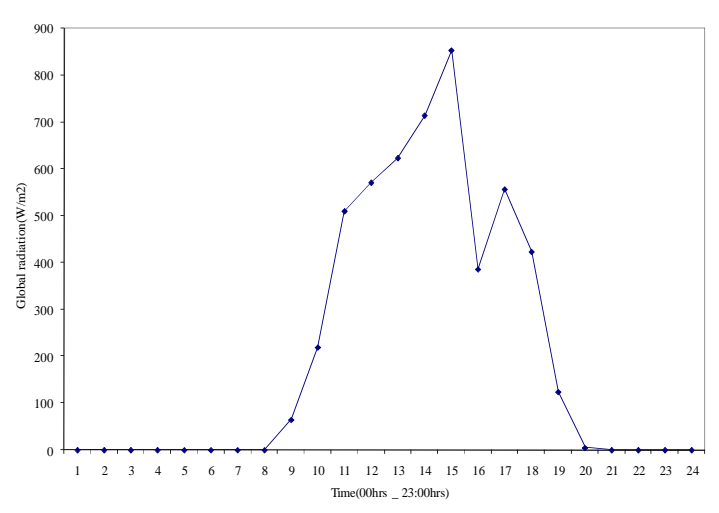

Fig. 12: Global radiation versus time $-19^{\text {th }}$ May 2006

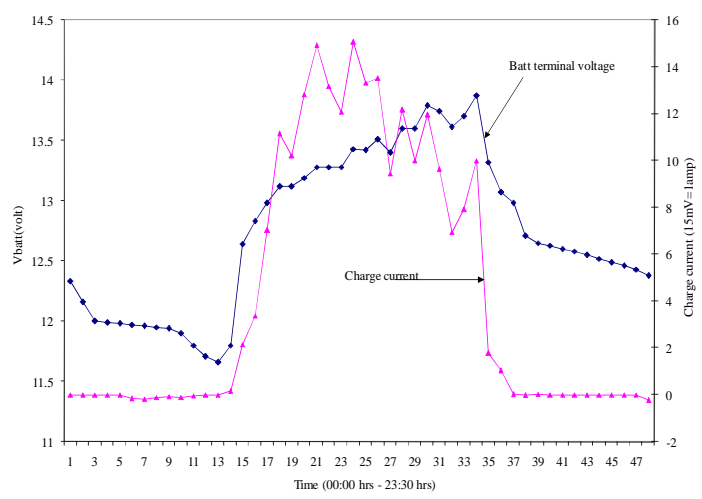

Fig.13: Battery terminal voltage and charge current versus time $-14^{\text {th }}$ July 2006

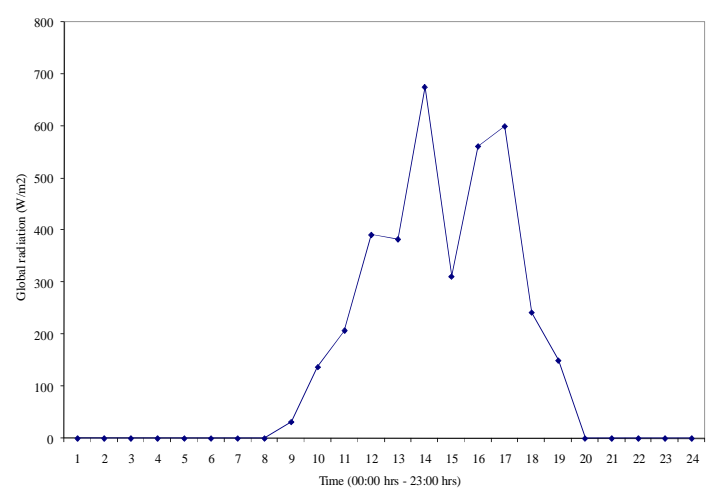

Fig. 14: Global radiation versus time $-14^{\text {th }}$ July 2006 


\section{DISCUSSION}

The charge controller entered the bulk charge stage after each overnight discharge. This is characterized by the high initial rate of charge shown on the daily charge/discharge curves of the initial and final settings. It must be noted that disconnecting the load by either the LVD or the dawn-dusk switch leads to a sudden increase in voltage. This also contributed to the initial steep rise in battery terminal voltage. The battery charged up using the maximum available current from the PV generator. The steep slope at the start of the charge current curve (Figures 9, 11, and 13) is indicative of the initial high current demand in the bulk charge stage. The battery voltage increased linearly but at a rate lower than the initial rate while the charge current basically leveled out and started to taper off. This is characteristic of constant current charge. The battery continued to charge until the PV generator power fell below the minimum necessary to sustain charging. For both settings, the battery consistently charged up to the minimum loadreconnect set-point before sunset thereby ensuring availability of lighting service (Figures 5, 7, 9, and 13).

Battery discharge consistently started between 18:00 and 18:30 hours. The discharge curves show that the LVD set points were not always reached implying an improved charge acceptance for that cycle (Figures 6, 7, 11, and 13).

With the initial regulation set-points, the electrolyte SG was virtually at 1.250 over the 150 daily cycles. Reduction in electrolyte level was insignificant; no distilled water was therefore added. However, the final regulation set-points, which were implemented over the following 120 daily cycles saw an increase in SG value (1.260, which remained almost constant) with nearly $40 \%$ decrease in electrolyte level $(4 \mathrm{~mm}$ out of the 10mm UPPER - LOWER mark on battery casing). The over-charge voltage (Voc) set-point was not reached for both settings though the SG value of 1.260 , for example, is within the 1.250 - 1.280 range for a fully charged flooded lead- acid battery in tropical climate (Siemens Solar Industries, 1998).

The total cost of the prototype battery charge controller, which includes the cost of the voltage sensing and charge control unit (US \$11.00), LVD switch (US \$5.00), dawn-dusk switch (US \$4.00), and miscellaneous costs (printed-circuitboard, heat-sink, casing) is estimated as US $\$ 38.00$. Comparatively, this is far less than the high-technology charge controllers, which currently cost about US $\$ 100.00$.

\section{CONCLUSION}

In this project, a simple and affordable prototype analog battery charge controller for small-sized stand-alone solar PV systems was designed, built and tested.

An actual solar PV lighting system was set up to evaluate the performance of the charge controller on an automotive battery. The performance of the constant current constant voltage algorithm for over 200 daily cycles was remarkable as the battery state of charge was maintained at acceptable levels ( $\mathrm{SG}=1.250-1.260)$ and the load management switches (LVD and dawn-dusk) functioned perfectly well. The test also showed that raising the regulation set-point values can lead to increased SG and higher electrolyte consumption. It can be deduced that attaining a particular battery state of charge is highly dependent on the regulation set-points and the $\mathbf{A} \mathbf{h}_{\mathbf{P V}} \mathbf{:} \mathbf{A} \mathbf{h}_{\mathbf{L o d}}$, ratio. The charge current and terminal voltage profiles and, in particular, the state of charge show that the controller-battery combination can sustain the load far beyond 300 additional daily cycles.

\section{ACKNOWLEDGEMENTS}

The authors are grateful to Prof. F.O Akuffo, Director of the Solar Energy Applications Laboratory (SEAL) of the Department of Mechanical Engineering, College of Engineering, KNUST for using the weather station and data logging facilities of this laboratory. They also acknowledge the invaluable assistance of Mr. Edwin Adjei of the same laboratory.

92 Journal of Science and Technology, Vol. 28, No. 2, August, 2008 


\section{REFERENCES}

Alber, G. (1998). "Predicting Battery Performance using internal cell resistance", pp 4.

990 South Rogers Circle, Ste. 11, Boca Raton, FL 33487. http://www.alber.com

Butler, D. (1997). "Lead-Acid Battery Charger Implementation Using PIC14C000".

Microchip Technology Inc. AN626, pp1.

Calabek, M., Micka, K., Baca, P., Kivak, P. and Smarda, V. (1996). "Resistance changes and premature capacity loss in lead battery plates", Journal of Power Sources, 62(2): 161-166.

Don, W., Howard, M.F, and Judith, G. (2003). "IEEE Guide for Selection, Charging, Test, and Evaluation of lead-acid batteries used in stand-alone Photovoltaic (PV) systems", IEEE Std 1361, IEEE Publications (ISBN: 0 -7381-3581-X).

Hans-Georg, P. and Dirk, U.S. (1996). "Optimisation of stand-alone PV System Design and Control Strategy". FraunhoferInstitut fur solare Energiesysteme ISE, puls@ise.fhg.de, sauer@ise.fhg.de.

Hollenkamp, A. F, Constanti, K. K, Huey, A. M, Koop, M.J, and Aputeanu, L. (1992). "Premature capacity-loss mechanisms in lead-acid batteries", Journal of Power Sources, 40(1-2): 125-136.

Instituto de Energia Solar, Madrid, Thermie (1998). "Universal Technical Standard for Solar Home Systems", B: SUP-995-96, pp11.
Kenneth, G., Daniel, W. (1997). “A Pulse-Width Modulated, High Reliability Charge Controller for Small Photovoltaic Systems”. Contractor Report, Sandia National Laboratories, SAND97-0329, pp 23.

Laszlo, B. (1999). "Implementing multi-stage charge algorithm with the UC3909 switch mode lead-acid charger controller". Application Note U-155, Unitrode Corporation.

Ministry of Energy, (2005). "Draft Code of Practice for off-grid PV systems", Ministry of Energy, Ghana, pp10.

Rahim, N.A., Mekhilef, S., Cam, E.L., and Ping, H.W.(2006). "Fuzzy-controlled battery charger state-of-charge controller". International Journal of Modeling and Simulation, 26(2): 106 - 111.

Rainer W. and Dirk U.S (2001). "Charge strategies for valve-regulated lead-acid batteries in solar power applications", Journal of Power Sources, 95(1-2): 141-152.

Siemens Solar Industries (1998). "PV Technology and System Design Training Manual", pp1021. http://www.siemenssolar.com

Tom, H. (2002). "Battery Testing for Photovoltaic Applications" Sandia National Laboratories, Albuquerque, NM 87185-0753, pp3.

Unitrode Corporation, (1999). "Improved charging methods for lead-acid batteries using the UC3906". Application Note U-104. 